than that given in the human studies. This effect in rats has been reported previously (Hoogland, Miya, and Bovsquet, 1966). It illustrates that great care must be taken in extrapolating the results obtained from animal screening studies of drug metabulism to man.

The importance of these studies is that it appears safe to administer these three benzodiazepines in these doses to patients on long-term warfarin therapy without encountering problems of drug interaction, which are so frequently found with other hypnotics and sedatives.

We acknowledge the help of Mrs. Wendy Watts, Mr. Larry Davies, Dr. Donald Davies, and Professor C. T. Dollery in these studies. We are grateful to Roche Pharmaceuticals for financial support, and to B.D.H. Pharmaceuticals for supplies of thrombotest reagent.

\section{References}

Breckenridge, A., Davies, D. S., Orme, M., and Thorgeirsson, S., (1969). Fournal of Physiology, 202, 15P.

Breckenridge, A., and Orme, M. (1971). Annals of the New York Academy of Sciences, 179, 421.

Breckenridge, A., Orme, M., Thorgeirsson, S., Davies, D. S., and Brooks, R. V. (1971). Clinical Science, 40, 351 .

Butler, P. W., Besser, G. M., and Steinberg, H. (1968). Fournal of Endocrinology, 40, 391.

Conney, A. H., Jacobson, M., Schneidman, K., and Kuntzman, R. (1965). Life Sciences, 4, 1091.

Dam, F. E. van, and Overkamp, M. J. H. (1967). Folia Medica Neerlandica, 10,141 .

Hoogland, D. R., Miya, T. S., and Bovsquet, W. F. (1966). Toxicology and Applied Pharmacology, 9, 116.

Lackner, H., and Hunt, V. E. (1968). American fournal of the Medical Sciences, 256, 368.

Lewis, R. J., Ilnicki, L. P., and Carlstrom, M. (1970). Biochemical Medicine,

Owren, P. A. (1959). Lancet, 2, 754

Robinson, D. S., and Sylvester, D. (1970). Annals of Internal Medicine, 72, 853 .

\title{
Factors Leading to Dependence on Hypnotic Drugs
}

\author{
A. D. CLIFT
}

British Medical fournal, 1972, 3, 614-617

\section{Summary}

Patients in general practice complaining of insomnia of recent origin have been studied in order to ascertain which factors may be of value in the detection of those more susceptible to drug dependence. The type of sleep disturbance was found to be of importance and a personal disturbance scale was found useful as a screening test in two-thirds of the patients. No difference was found in the development of dependence on amylobarbitone and nitrazepam. One of the most important factors in the prevention of drug dependence seems to be frequent review by the doctor after the first prescription and his cautionary advice to the patient.

\section{Introduction}

Barbiturate dependence of varying severity has been known for many years since the account of Clarke (1904). Physical dependence with major withdrawal symptoms was described experimentally by Isbell (1950) in the U.S.A. and recognized clinically by Wulff (1959) in Denmark. Isbell et al. (1950) and Essig (1967) showed that a daily dose of at least $400 \mathrm{mg}$ of a barbiturate is necessary to produce a clinically significant abstinence syndrome when the drug is withdrawn.

Many patients taking barbiturate and other hypnotics regularly in small dosage never show clinical evidence of physical dependence (Johnson and Clift, 1968) and, as stressed by Tatum and Seevers (1931), psychological factors are basic in drug dependence. Drug dependence has been described as a desire to take the drug in order to experience its psychic effects (Expert Committee on Drug Dependence, 1969). It has been pointed out (Seevers and Deneau, 1964) that a need exists to determine the characteristics of individuals likely to develop drug dependence.

Prescribing patterns of psychotropic drugs in general practice were reviewed by Parish (1971), who noted the rapid rise in

the use of nitrazepam. Glatt (1969) maintained that no case of definite psychological or physical dependence on this drug had come to light, and in a review of psychotropic drugs Dally (1970) stated that "addiction to nitrazepam does not occur." The large number of prescriptions for hypnotic drugs in the National Health Service (18.8 million in 1970; Department of Health and Social Security, 1972), of which an increasing proportion are for non-barbiturate hypnotics, suggested that a prospective study of patients taking hypnotic drugs might give answers to three questions. (1) Do the non-barbiturate hypnotic drugs as represented by nitrazepam give rise to dependence, and if so is this as likely to occur as with amylobarbitone ?; (2) Are there measurable social, demographic, psychological, or personality-type characteristics which distinguish subjects who develop hypnotic drug dependence from those who do not ?; (3) Is nitrazepam as acceptable as amylobarbitone to patients with insomnia?

\section{Present Study}

The patients came from a three-handed general practice in a mainly urban and industrial area of south-east Lancashire. Only patients over the age of 15 years were included from a total list of 7,600 , the population at risk being then 5,760 .

Two groups of patients were studied; the findings in the first suggesting more detailed examination of the second. Patients were not admitted to either group unless other methods of treating their insomnia had seemed inadequate-for example, analgesics for pain-and the patient still demanded hypnotic drugs.

\section{GROUP 1}

Fifty patients presenting consecutively with a recent complaint of insomnia were prescribed a non-barbiturate hypnotic drug by one of the doctors; 43 received nitrazepam, 4 diazepam, and 3 glutethimide. They were not given any special advice about drug dependence and received repeat prescriptions as they felt they required them. Cases were reviewed by me at six months and one year. 
GROUP 2

Patients attending the practice with a recent complaint of insomnia were referred to me for possible inclusion in the trial. Details taken included age, sex, marital and social status, past psychiatric and medical history, use of tea and coffee, previous use of hypnotic drugs, and the patient's description of the sleep disturbance in his own words. Patients were excluded from the study if a hypnotic drug had been used within the previous three months or if any other member of the household was currently taking hypnotic drugs. Altogether 108 patients were selected.

The cause of the insomnia was looked for and recorded as "medical" if due to an underlying medical or surgical disability, "psychiatric" if due to a psychiatric illness, "extraneous" if due to some outside cause such as noise, cold, or uncomfortable bed, or "normal psychological" if thought to be due to anxiety regarded by the doctor as having a reasonable cause and as not being unduly prolonged or severe. Some patients could not be fitted into these categories, there being no apparent cause for the insomnia, which was of onset type-that is, simply difficulty in getting to sleep, and these were classified as "simple onset insomnia."

A personality assessment was made based on knowledge of the patient, past records, and the impression given by the patient in describing the presenting symptomatology. In this survey the patients were classified according to the character traits described under "Personality Disorder" in the glossary of mental disorders of the General Register Office (1968). One other trait not in this classification was used-namely, that of the anxious, worrying type of personality.

The personal disturbance scale (short version) (Foulds and Hope, 1968) was used at the initial interview in all cases. This scale is a shorter version of the symptom-sign inventory of Foulds (1965), which was compiled as an aid to the differential diagnosis of the mentally ill. The shorter version has been considered as a possible screening device in epidemiological and social surveys (Foulds and Hope, 1968). It consists of 20 questions, and the score on the scale is the sum of the items to which the response is positive. Examples of the type of question asked are: "Have you lost interest in almost everything ?", and "Do you often feel puzzled, as if something has gone wrong either with you or with the world, without knowing just what it is ?"

If patients who become dependent on hypnotic drugs are mentally disturbed then it was thought that they would score significantly higher on this scale than those who do not become dependent, but if mental disturbance was not related to drug dependence there would be no significant difference.

Administration and marking of this questionnaire proved straightforward. The patient was told that it would enable the doctor to find out more about him and perhaps be able to treat his insomnia more appropriately. All the patients co-operated.

Amylobarbitone $100 \mathrm{mg}$ or nitrazepam $5 \mathrm{mg}$ was prescribed according to a planned random sequence and patients were given the following advice: "It is considered desirable to manage without sleeping tablets as soon as possible, and you are encouraged to manage without them if you can. However, if you feel you need them, we will continue to supply prescriptions. Please remember to attend your next appointment."

Follow-up.-Patients were seen again two, six, and 12 weeks after the original prescription and asked for details about sleep, use of the hypnotic drug, and the original cause of the insomnia. A further prescription was given if the patient thought he needed it. A final review was made one year after the original prescription.

\section{Results}

In interpreting the results the term "dependent" implies only that the patient continued to take the drug at any particular time in the study. If not otherwise stated this was six weeks or more from the first prescription.

\section{GROUP 1}

Six months after the initial prescription $17(34 \%)$ patients in group 1 were still requesting regular prescriptions for hypnotic drugs. One year after the initial prescription this number was reduced to $16(32 \%)$.

\section{GROUP 2}

Of the original 108 patients in group 2, 102 were finally followed up. It was found that exactly equal numbers had been prescribed amylobarbitone and nitrazepam (51 patients each). The falling off in the number of patients still requesting hypnotic drugs at increasing intervals of time is shown in the Chart. Only eight patients were still taking the drug one year after the original prescription, five taking nitrazepam and three amylobarbitone.

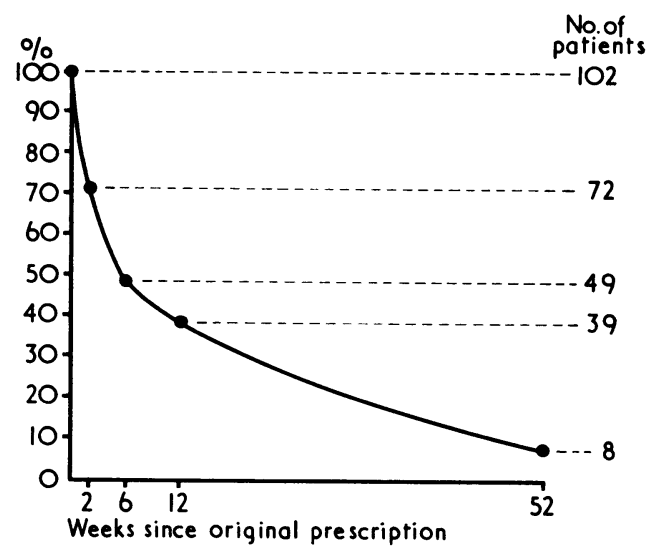

Use of hypnotics by patients in group 2 over one year.

The difference in prescribing between groups 1 and 2 was highly significant $\left(\chi^{2}=14.64, P<0.001\right)$.

Drug Effectiveness.-Both amylobarbitone and nitrazepam proved satisfactory. Only six patients (four on amylobarbitone and two on nitrazepam) felt that the drugs had not improved sleep to their satisfaction. Only eight patients $(7 \%)$ experienced hangover effects, and in this respect there was no difference between the two drugs. In view of the very slow metabolism of nitrazepam (Oswald, 1969) it was thought that there might be a difference in frequency of taking the hypnotic. This was assessed at six weeks but the two drugs were in fact used in a very similar way. Most took the tablet every night $(53 \%)$ or every other night $(29 \%)$.

\section{Characteristics of Dependent Subjects}

No significant differences between the sexes were found, but males under 45 years were more likely to develop dependence than men starting the hypnotic at a greater age.

All the six unmarried people were in the non-dependent group. There was no evidence that widowed and divorced people were more likely to become dependent. The previous medical and psychiatric history and the use of caffeine at night were not found to be of significance as pointers towards dependence.

All five alcoholics in the survey were men and all became dependent, using either hypnotic drugs or alcohol indiscriminately at night. Four patients who were pregnant discontinued 
the drug immediately after confinement and none became dependent.

A larger number of dependent patients than non-dependent patients gave a history of previous hypnotic drug usage, and this was statistically significant (Table I). In most cases the drug had been taken over a year previously but was just as likely to have been a barbiturate as a non-barbiturate.

TABLE I-Previous Hypnotic Drug Usage in Dependent and Non-dependent Patients in Group 2

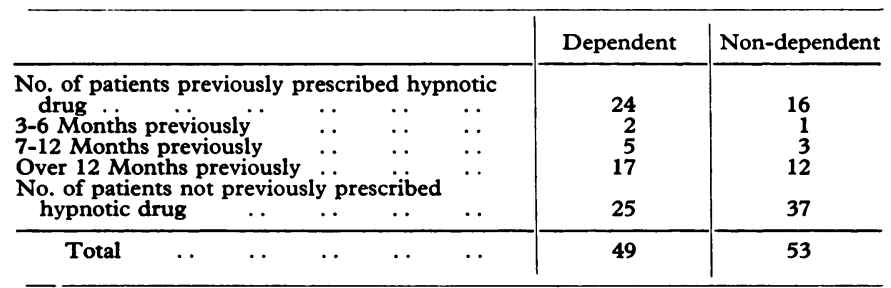

$x^{2}=4.448 ; P<0.05$.

The development of dependence according to diagnostic group is shown in Table II ; the results just fail to reach statistical significance.

TABLE II-Cause of Insomnia in Dependent and Non-dependent Patients in Group 2

\begin{tabular}{|c|c|c|c|c|c|c|}
\hline & & & $\begin{array}{c}\text { No. of } \\
\text { Patients }\end{array}$ & $\%$ & Dependent & $\begin{array}{c}\text { Non- } \\
\text { dependent }\end{array}$ \\
\hline $\begin{array}{l}\text { Medical .. } \quad . . \\
\text { Psychiatric } \\
\text { Normal psychological } \\
\text { Simple onset insomnia } \\
\text { Extraneous stimuli }\end{array}$ & $\begin{array}{l}\ldots \\
\cdots \\
\cdots \\
\cdots\end{array}$ & $\begin{array}{l}\ldots \\
\because \\
\because \\
\therefore\end{array}$ & $\begin{array}{r}27 \\
40 \\
25 \\
10 \\
0\end{array}$ & $\begin{array}{r}26 \cdot 5 \\
39 \cdot 2 \\
24 \cdot 5 \\
9 \cdot 8\end{array}$ & $\begin{array}{r}10 \\
24 \\
15 \\
0 \\
0\end{array}$ & $\begin{array}{r}17 \\
16 \\
10 \\
10 \\
0\end{array}$ \\
\hline Total & $\cdots$ & $\ldots$ & 102 & $100 \cdot 0$ & 49 & 53 \\
\hline
\end{tabular}

$\chi^{2}=7.44 ; 0.05<P<0.1$ (3 D.F.)

In each social class the number of dependent and nondependent patients was nearly the same.

Most patients $(80 \%)$ were thought to exhibit abnormal personality traits but no significant differences between dependent and non-dependent groups could be found.

The mean personal disturbance score for dependent patients was found to be significantly higher than that for non-dependent patients (Table III), and various cut-off points in the score were tried in order to find the most useful one for detecting dependence-prone patients. A cut-off point of $6+$ (scores of 6 and over

TABLE III-Mean Personal Disturbance Score in Dependent and Non-dependent Subjects at Six Weeks (Group 2)

\begin{tabular}{|c|c|c|c|c|}
\hline & \multicolumn{2}{|r|}{ Males } & \multicolumn{2}{|c|}{ Females } \\
\hline & $\begin{array}{c}\text { Dependent } \\
(\mathrm{n}=19)\end{array}$ & $\begin{array}{c}\text { Non-dependent } \\
(n=19)\end{array}$ & $\begin{array}{l}\text { Dependent } \\
(\mathrm{n}=30)\end{array}$ & $\begin{array}{c}\text { Non-dependent } \\
(n=34)\end{array}$ \\
\hline Score \pm S.D. & $7 \cdot 47 \pm 4 \cdot 52$ & $5 \cdot 26 \pm 3 \cdot 46$ & $7 \cdot 26 \pm 4 \cdot 26$ & $4 \cdot 29 \pm 3 \cdot 69$ \\
\hline Significance & $t=2.395 \quad(36$ & D.F.); $P<0.05$ & \multicolumn{2}{|c|}{$t=2.90$ (62 D.F.); P $<0.01)$} \\
\hline
\end{tabular}

count as high) gave male sensitivity as $73.8 \%$ (that is, the test would miss $26 \cdot 2 \%$ of dependence-prone subjects) and female sensitivity $63.3 \%$ (that is, the test would miss $36.7 \%$ of dependence-prone subjects), and male specificity as $64.1 \%$ (that is, the test would incorrectly identify $36.9 \%$ of normals as dependence prone) and female specificity as $73.5 \%$ (that is, the test would incorrectly identify $26.5 \%$ of normals as dependence prone). The score was of most value in the "medical" and "normal psychological" diagnostic groups, whereas in the "psychiatric" group it was high in both dependent and nondependent patients.
A mixed type of insomnia (waking off and on throughout the night with both onset insomnia and early waking) was much commoner in dependent patients, whereas onset insomnia was more commonly associated with non-dependence (Table IV).

TABLE IV-Type of Insomnia in Dependent and Non-dependent Patients in Group 2

\begin{tabular}{|c|c|c|c|c|c|c|}
\hline \multirow{2}{*}{$\begin{array}{c}\text { Type } \\
\text { of } \\
\text { Insomnia }\end{array}$} & \multicolumn{2}{|c|}{ Males } & \multicolumn{2}{|c|}{ Females } & \multicolumn{2}{|c|}{ Total } \\
\hline & Dependent & $\begin{array}{c}\text { Non- } \\
\text { dependent }\end{array}$ & Dependent & $\begin{array}{c}\text { Non- } \\
\text { dependent }\end{array}$ & Dependent & $\begin{array}{c}\text { Non- } \\
\text { dependent }\end{array}$ \\
\hline $\begin{array}{l}\text { Onset } \\
\text { Early }\end{array}$ & 3 & 12 & 9 & 15 & 12 & 27 \\
\hline $\begin{array}{l}\text { wakening } \\
\text { Mixed }\end{array}$ & $\begin{array}{l}7 \\
9\end{array}$ & $\begin{array}{l}4 \\
3\end{array}$ & $\begin{array}{r}8 \\
13\end{array}$ & $\begin{array}{r}9 \\
10\end{array}$ & $\begin{array}{l}15 \\
22\end{array}$ & $\begin{array}{l}13 \\
13\end{array}$ \\
\hline Total & 19 & 19 & 30 & 34 & $49 *$ & $53^{*}$ \\
\hline
\end{tabular}

$* \chi^{2}=9.4610 ; \mathrm{P}<0.01$ (2 D.F.)

\section{Discussion}

The low dependence rate after one year in group 2 might have been related to the small dose of drug used (amylobarbitone $100 \mathrm{mg}$ or nitrazepam $5 \mathrm{mg}$ ), for Evans and Ogunremi (1970) showed that if the dose of a hypnotic is low enough it might not reach the "threshold" at which rapid eye movement sleep is reduced with subsequent development of rebound phenomena when the drug is withdrawn. However, patients in group 1 taking nitrazepam were prescribed the same dose, and in this group $32 \%$ were dependent after one year. Perhaps the most likely explanation for the difference is in the cautionary advice given to group 2 patients, to the effect that the drug should be discontinued as soon as possible. No such advice was given to the patients in group 1. Thus psychic dependence may be averted if the patient is motivated against the long-term use of drugs even if prescriptions are made available.

It seems then that about a third of patients starting on hypnotic drugs may become dependent on them in low dosage for a long period if no effort is made by the general practitioner to discontinue them. Some of those who stop taking them probably start again at a later date, and as shown in Table I threefifths of those who restart sleeping tablets after an interval of time continue taking them for at least six weeks, and this applies particularly to females. This astonishingly high dependence rate presumably accounts for the massive total of prescriptions for hypnotic drugs in the National Health Service.

As equal numbers of patients in group 2 discontinued amylobarbitone or nitrazepam before the six-week assessment it is likely that in the small dosage used there is an equal chance of being dependent on either drug at that stage. The drugs also proved equally effective as hypnotics, and of the 49 patients taking the drug after six weeks only 13 had found it necessary to increase the dose from one to two tablets. Davies and Levine (1967) have already shown the efficacy of this small dose of hypnotic, and in view of the equal effectiveness of the two drugs there can be little place for the continued prescribing of barbiturate hypnotics with the risk of chronic toxic effects and of self-poisoning by overdose (Kessel, 1965). Only one patient in the trial (in group 2) took an overdose, and this was of amylobarbitone. The great safety of nitrazepam in overdose (Matthew, 1970) must still make it the hypnotic of choice despite the fact that patients are as likely to become dependent on it as they are on barbiturates.

This study suggests that dependence on hypnotic drugs need not be a major problem, as shown by the number of patients in group 2 still taking the drugs after one year. It does, however, reveal differences between those capable of discontinuing the drug early and the others, and as it is from this latter group that those ultimately dependent will come its distinguishing features are of interest. 
The fact that social or demographic features were for the most part not helpful in distinguishing the dependence-prone patient implies that they are drawn from all sections of the community. The average age, however, was high ( 48.2 years for dependent and 49.5 years for non-dependent patients in group 2). It is probable that young people do not often ask the family doctor for hypnotic drugs; nevertheless, as shown in a previous paper (Johnson and Clift, 1968) it is in the younger patients that severe dependence with physical withdrawal symptoms may develop. Their characteristics are possibly different from the patients in the present survey.

Although $80 \%$ of the subjects showed evidence of abnormal personality traits equal numbers of these became dependent or remained non-dependent, and no particular personality trait predominated in the dependent group. Abnormal personality traits are often associated with insomnia and the need to take hypnotics but their presence does not help in the prediction of those prone to dependence on hypnotic drugs.

Those patients with low personal disturbance scores were much less likely to continue taking the drug longer than six weeks, and if the doctor wishes to exercise discretion in the prescribing of hypnotic drugs the application of the personal disturbance scale could be of help in screening for the dependence prone. If the drug were withheld from those with a score of 6 or over, this group would include a number of patients (up to a third) who would not in any case have continued taking the drug longer than six weeks, but two-thirds of those likely to do so would have been selected out. The scale is not therefore very sensitive when used in this capacity but may have limited value by helping to select a group in which are to be found many of those likely to request repeat prescriptions for hypnotic drugs. Time spent in follow-up and cautionary advice on the use of drugs may be especially valuable in these patients.

In the presence of a psychiatric illness the personal disturbance score is of little value in distinguishing dependence-prone patients from others, and this study has not shown why a number of patients with psychiatric illness and a high mean personal disturbance score nevertheless discontinued the hypnotic drug. The explanation may be in the effect of other treatment, mainly antidepressant drugs, and it has been shown elsewhere (Bond et al., 1970) that the insomnia of depressive illness may be adequately controlled by appropriate physical treatment. Perhaps it is easier to treat depressive illness than to alleviate the natural anxiety arising from a "normal psychological" situation where the underlying cause-for example, unfaithfulness in a spouse-remains more intractable.

The increased risk of dependence apparent in patients with a mixed type of insomnia and the association of this type of insomnia with endogenous depression (Hinton, 1963) implies that caution should be exercised in the prescribing of hypnotic drugs to patients with depressive illness.

Dependence on hypnotic drugs in general practice varies widely, from the $25 \%$ quoted by Abrahams et al. (1970) in Brisbane to the $1.3 \%$ in five Manchester practices (Johnson and Clift, 1968). The disparity in numbers becoming dependent in the two groups reviewed in the present study underlines the importance of the doctor's attitude towards drug prescribing, and it seems highly likely that a cautious attitude towards the taking of sleeping tablets was transmitted to the patients in the second group, many of whom volunteered remarks such as "I don't like taking drugs, of course," or "I don't want to stay on tablets."

One other factor of interest in the present study was the complete absence of "extraneous" causes for insomnia. If cold, discomfort, noise, etc. disturb a patient's sleep then he does not appear to come to the doctor for treatment; most patients who do present have a psychiatric or psychological cause for their insomnia.

The dangers of barbiturate dependence have been discussed for the past 50 years. Perhaps Willcox (1927) was not far from the truth when he wrote "they should be given only on prescription, to be retained by the pharmacist, and the total number of doses ordered should not exceed six. The patient should be warned against daily use of the drug." Most practitioners would regard Willcox as overcautious, but it certainly seems that regular supervision and a suitable caution given to the patient are some protection against dependence on hypnotic drugs. The gradual transition, however, towards the prescribing of nonbarbiturate hypnotic drugs is unlikely to be associated with any fall in drug dependence on that account alone.

I wish to thank my partners, Dr. D. Brooks and Dr. J. A. Maudar, for providing patients for this study, and Professor Neil Kessel and Dr. J. Johnson, of Manchester University, for their helpful advice. Some aspects of this paper were taken from my $\mathbf{M}$. D. Thesis (1971).

\section{References}

Abrahams, M. J., Armstrong, J., and Whitlock, F. A. (1970). Medical fournal

Bond, M. R., Pearson, I. B., and Seager, C. P. (1970). British Medical fournal, 3, 586.

Clarke, G. F. M. (1904). Lancet, 1, 223.

Dally, P. (1970). Practitioner, 205, 307.

Davies, C., and Levine, S. (1967). British Fournal of Psychiatry, 113, 1005.

Department of Health and Social Security (1972). Annual Report, 1971, Table 14. London, H.M.S.O.

Essig, Carl F. (1967). Epilepsia, 8, 21.

Evans, J. I., and Ogunremi, O. (1970). British Medical fournal, 3, 310.

Expert Committee on Drug Dependence (1969). World Health Organization Technical Report Series, No. 407.

Foulds, G. A. (1965). Personality and Personal Illness. London, Tavistock.

Foulds, G. A., and Hope, K. (1968). Manual of the Symptom-Sign Inventory (S.S.I.). London, University of London Press.

Glatt, M. M. (1969). Lancet, 2, 429. General Register Office (1968). Studies on Medical and Population Subjects,
No. 22. London, H.M.S.O.

Hinton, J. M. (1963). Fournal of Neurology, Neurosurgery and Psychiatry, 26, 184.

Isbell, H. (1950). Annals of Internal Medicine, 33, 108.

Isbell, H., et al. (1950). Archives of Neurology and Psychiatry, 64, 1

Isbell, H., et al. (1950). Archives of Neurology and Psychiatry, 64, 1.

Johnson, J., and Clift, A. D. (1968). British Medical

Kessel, N. (1965). British Medical fournal, 2, 1336.

Oswald, I. (1969). Nature, 223, 893 .

Parish, Peter A. (1971). Fournal of the Royal College of General Practitioners, Suppl. No. 4, p. 21 .

Seevers, M. H., and Deneau, G. A. (1964). Handbook of Physiology. ed. D. B. Dill, E. F. Adolph, and C. G. Wilber, Section 4, p. 809. Washington, American Physiological Society.

Tatum, A. L., and Seevers, M. H. (1931). Physiological Reviews, 11, 107.

Willcox, W. (1927). Proceedings of the Royal Society of Medicine, 20, 1479

Wulff, M. H. (1959). Electroencephalography and Clinical Neurophysiology Suppl. No. 14. 